\title{
The street lamp intelligent management system based on elastic compute service
}

\author{
Jing Liu ${ }^{a}$, Yulin $\mathrm{Qi}^{\mathrm{b}}{ }^{\mathrm{b}}$, Zimeng Wang ${ }^{\mathrm{c}}$, Zeli Qi ${ }^{\mathrm{d}}$ \\ School of North China Electric Power University, Baoding 071003, China \\ a951220813@qq.com, ${ }^{\text {a } q i y u l i n 589 @ 163 . c o m,{ }^{c} 1165667982 @ q q . c o m,{ }^{d} 526877160 @ q q . c o m}$
}

Keywords: Urban Lighting, Intelligent Management, GPRS, Elastic Compute Service.

\begin{abstract}
Urban lighting systems as a sign of urban civilization, is becoming more and more important role. But the planning and management of urban street lighting equipment in most parts of our country is still in a very backward state. In order to improve the backward situation, save energy, increase the efficiency in the use of the street lamp, and promote the development of urban civilization, in this paper, aiming at the requirements of urban modernization of street smart monitoring system development, combined with the actual situation and proposed the street lamp intelligent management system based on elastic compute service, applies the General Packet Radio Service wireless communication technology combined with the elastic compute service in the management system, which made it comes to a realization of wireless real-time communication between the epigenous machine and the lower position machine, completed a visualization, graphical management of lighting terminal equipment to make the management of urban lighting system more humanization, intelligent and automation.
\end{abstract}

\section{Introduction}

Automated and intelligent management of urban lighting system has become one of the hallmarks of urban modernization. With the popularity of modern urban civilization and the development of science and technology, achieving urban lighting automation and intelligence has become our primary task now. According to the activity of "China Green Lighting Project" energy saving and environmental protection, our country promoting, the establishment of lighting control management system is imperative. The work includes intelligent and scientific control lamp opening or closing time and the lamp quantity, fixed and timely check the states of street lighting.

LED is the most promising solid green light source, emerging in recent years. LED has many advantages, such as small size, low power consumption, long life and environmental protection, as well as low voltage driving, fast response time and so on ${ }^{[1-2]}$. How to make street lamps light up, let the city lights up, light more scientific, light more saving energy and money, which requires a high level of lighting design and excellent quality of lighting equipment, besides a safe, reliable, flexible intelligent management system. Thus according to the different environment, different functions and different lighting needs, and the combination of the prepared different control programs, it can create a variety of lighting effects.

\section{Overall system design}

From the whole street lamp intelligent management system design, PC part mainly includes computer hardware, printer, switch, router, firewall and other hardware and database system, management system, etc..The lower part of the machine is composed of a centralized controller, a single lamp node and other hardware components.Subdivided into the street lamp terminal, wireless data transmission network and remote management center and other parts, the overall structure of the system is shown in figure 1.Concentrator through receiving and execution, forwarding the command of PC management software, to every single lamp control to control every street lamp lights off and dimming, save electrical energy ${ }^{[4]}$. 


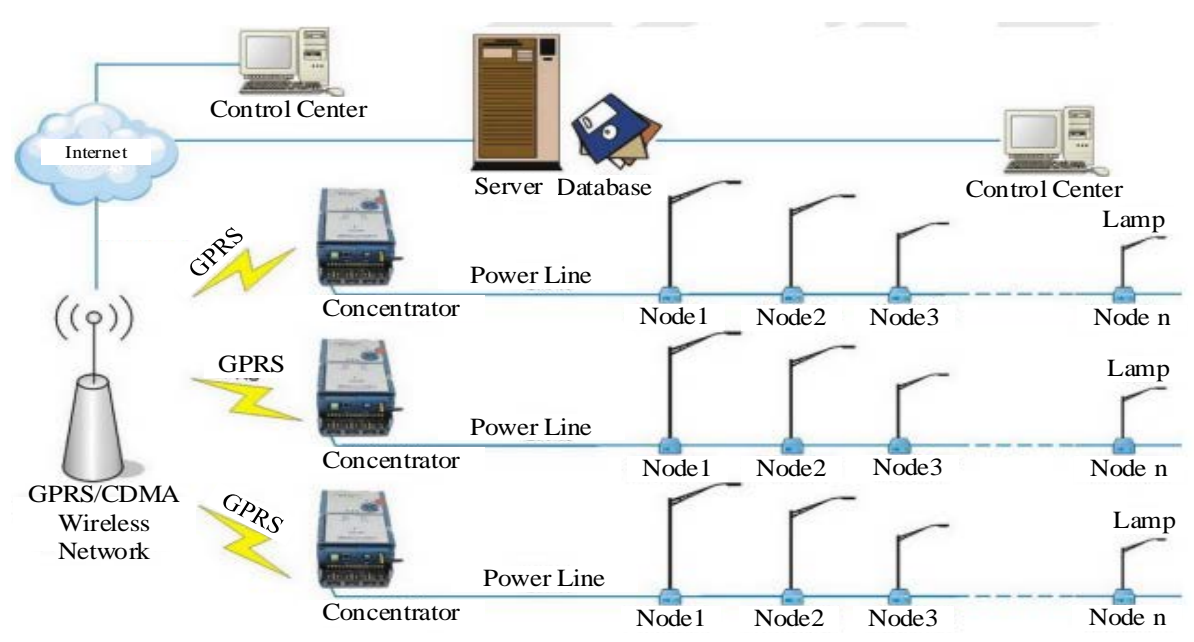

Fig.1 overall structure of the system

\subsection{Street Lamp Terminal}

In street lighting control of a street, for example, there must be more of a street lamp $\mathrm{N}$ single node distance is limited in scope (of the type concentrator transmission distance of 700 meters) for a single lamp mounting concentrator and GPRS modules.Concentrator via the built-in serial port connected with GPRS, uplink and downlink data transfer via the serial port. Monitoring terminal simple Schematic shown in igure 2 and figure 3.

The GPRS use models for KS-97 embedded module, as shown in Figure 2 U4. This module the pin type structure makes the product user does not need to change the software can get stable and sound GPRS/CDMA remote data communication function and message communication function within the shortest time. In the following design principle, the input voltage of the $220 \mathrm{~V}$ is reduced to GPRS to protect the normal operation of the $4.2 \mathrm{~V}$ by using some power conversion modules (such as Figure 2 U1, U2), capacitance resistance and inductance. After power on GPRS according to set the server address and port active and data center server connection, connection will immediately to the server to send the registration package (registration packet content defined by the user, through the configuration tool set), registered package allows server identifies the current terminal ID. Between the server and the terminal can be transparent to transmit arbitrary data. At the same time, the client can send commands to GPRS, such as sending text messages, modifying parameters, query parameters, and so on.

The concentrator is types of BM100N low-power distributed wireless mobile ad hoc network module, as shown in Figure $2 \mathrm{U} 4$, work $430 \mathrm{~m}$ or $470 \mathrm{~m}$ band in, working voltage range 2.0V 3.6V, baud rate 2400 230400bps and message format settings flexible, support for multiple protocols and embedded wireless mobile ad hoc network discussion wave mesh. Design by $5 \mathrm{~V}$ turn 3.2V module (such as Figure $2 \mathrm{U} 3$ ) to the input voltage of the concentrator $3.2 \mathrm{~V}$, concentrator and GPRS serial connected, installation SIM card power can work. In the monitoring terminal, each single lamp is equipped with voltage transformer and current transformer real-time collection of various sections of the single lamp lights / DC voltage, current and other parameters and the data acquisition were analyzed and converted into; and then the results will be through the concentrator port is sent to the GPRS module block, at the same time, through the cloud server for receiving and transmitting from the control command of the monitoring center, make the corresponding operation.

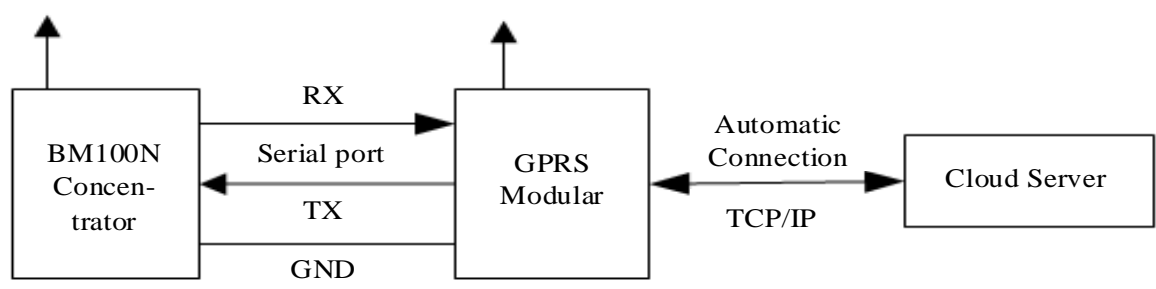

Fig. 2 Schematic diagram of monitoring terminal 

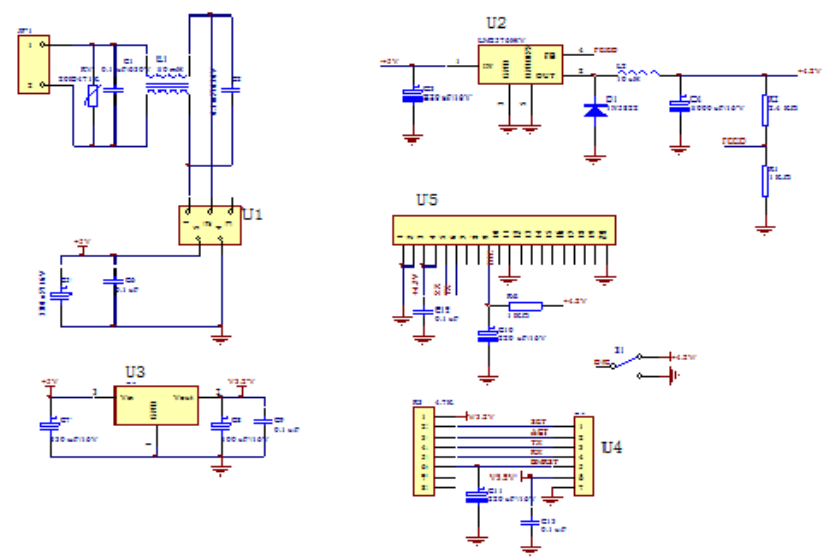

Fig. 3 Detailed pin diagram

\subsection{Wireless Data Transmission Network}

The system design does not have fixed IP server, it is necessary to design the cloud server to forward GPRS upload data and monitor management center station issued the operation command.GPRS module and management center station automatically connect to the cloud server site to achieve communication. The structure diagram of the wireless data transmission part is shown in figure 4. Fixed IP cloud server design software flow chart is shown in figure 5.The whole design uses the message bus service to form a real-time and stable set control work mode. Message bus theory support unlimited client (the management center and GPRS) access, cloud server configuration design mapping to achieve a management center control arbitrary multiple GPRS module, a GPRS module is influenced by multiple management center management.The client connects the server, reported ID and verification, after the success of the server is labeled, and read the mapping configuration, into the working state.The connection and forwarding of the system is shown in figure 6.

GPRS is an efficient and low cost wireless packet data service. Its theoretical bandwidth of up to $171.2 \mathrm{Kbps}$, in this channel to provide TCP/IP connection, to provide mobile users with high-speed wireless IP or X.25 services ${ }^{[5-6]}$.

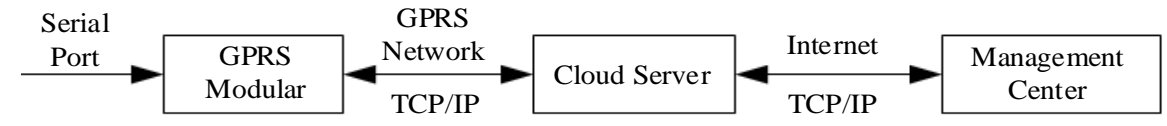

Fig. 4 Schematic diagram of wireless data transmission

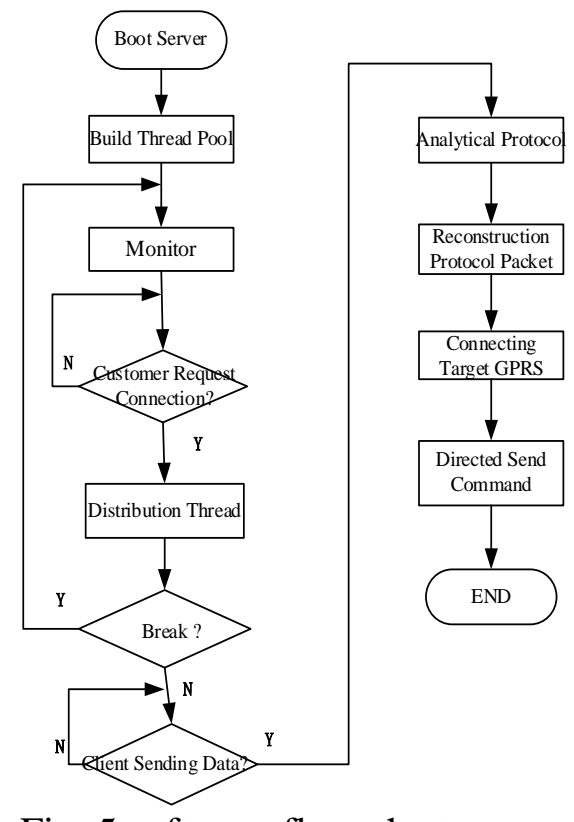

Fig. 5 software flow chart

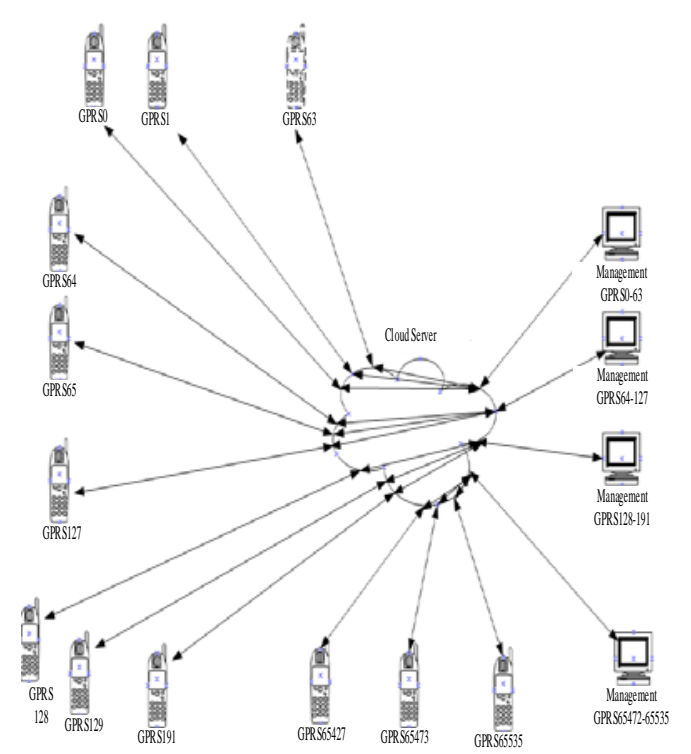

Fig. 6 connection and forwarding relationship 


\subsection{Remote Management Center}

Remote monitoring and controlling system for the remote monitoring software running on the client computer. Be able to grasp the running state of the street lamp in time and carry out independent intelligent control. Management center software mainly includes the following modules design:

Intelligent graphics module: the system can be according to the actual situation of the distribution of intelligent graphics, Staff can directly see the running state of the street lamp, more convenient for the management and control of the staff.

Remote query module: the system can detect any single lamp AC / DC voltage, current, power and other parameters of information and display in the system interface edit box, easy to get the user to get street lights.

Remote control module: This module mainly includes management led drive reset, LED driver management stop trigger, low light operation and super low light operation, street lamp brightness interval, unilateral light function. After the user clicks on the corresponding control button, the system sends out the corresponding control commands, and the street lamp receives the command to perform the corresponding operation.

Found in which single node of the lamp value to appear the unusual, think street lamps malfunction. The system automatically sends out sound and light alarm.

\section{Conclusions}

The GPRS Remote Technology and cloud servers combined design concept and the use of database technology for lamp establish archives for the design of the street lamp intelligent management system based on cloud services, after testing GPRS connection time server for 30s, the management center to send a server command server switching time is $2 \mathrm{~S}$, street lamps response time to about 10s. The whole design can timely, to grasp the operation status of the entire city street light, and the corresponding intelligent control of street lamp, reducing management costs, improve the street lamp management level and the quality of services, is of great significance in energy conservation and environmental protection ${ }^{[7]}$.

\section{Reference}

[1] Li Baojun,Mou Daming, Yao Yiliang, Tian Songlin. LED street lamp and high pressure sodium lamp efficiency comparison analysis[J]. Journal of lighting engineering. Vol. 2011, No. 06, p.8.

[2] Chen Shangwu, Chen Min, Qian Zhaoming. High brightness LED solar street lamp lighting system. Power electronics technology, Vol. 40 (2006), No. 06, p. 43-45.

[3] Wang Chengfu, Tang Xiaoqiang. Design and implementation of GPRS based street lamp monitoring system [J]. power system communication.Vol. 29 (2008), No. 190, p.:18-21.

[4] (Xu Yongmao:Research on the management of urban lighting system based on GPRS( Master of Engineering,Northwestern Polytechnical University,2006).p.20.)

[5] Zhu Ronghui, Wu Aiguo. Development of urban lighting monitoring system based on GPRS[J].Vol. 24 (2005), No.12, p: 100-103.

[6] (Li Yan :GPRS application in street light monitoring systems (Master of Engineering,Dalian University of Technology,2007).p.34.)

[7] Zhou Feng, Wang Chenguang. Based on GPRS / GSM streetlight monitoring system [J]. Industrial Instrumentation \& Automation Vol.(2008), NO.1,p:18-20. 